\title{
Social and Institutional issues in the Adoption of School-based Technology-aided Sexual Health Education Program
}

\author{
Angella Musiimenta ${ }^{1}$ \\ 1 Mbarara University of Science and Technology, and Bishop Stuart University Kakoba
}

\begin{abstract}
Objective: School-based sexual health education interventions can reach young people of diverse backgrounds and equip them with knowledge and skills for protecting themselves against HIV/AIDS, unwanted pregnancies, and live healthy and responsible lives. However, given that school-based sexual health education intervention are health projects implemented in educational settings, variety of social and institutional issues can present challenges. This study aimed to obtain rich insights into the facilitating or inhibiting mediators for the implementation of a schoolbased sexual health education intervention in Uganda.
\end{abstract}

Method: This study conducted 16 qualitative interviews to investigate the mediators for the implementation of the school-based sexual health education intervention based on experiences of two Ugandan schools: the school which successfully completed the implementation of the intervention, and the school which abandoned the intervention half-way the implementation.

Results: Rather than the technological aspects, results indicate that the implementation was strongly influenced by interplay of social and institutional mediators, which were more favourable in the "successful" school than in the "failure school". These mediators were: perceived students' vulnerability to HIV and unwanted pregnancies; teachers' skills and willingness to deliver the intervention, management support; match with routine workflow, social-cultural and religious compatibility, and stakeholder involvement.

Conclusion: Rather than focusing exclusively on technological aspects, experiences from this evaluation suggest the urgent need to also create social, institutional, and religious climate which are supportive of school-based computer-assisted sexual health education. Evidence-based recommendations are provided, which can guide potential replications, improvements, and policy formulation in subsequent school-based sexual health education interventions.

Key words: sexual health education; school health education; adolescents' sexual health; teacherstudent sex education; informatics.

Correspondence: angellamusiimenta@yahoo.com

Copyright @2013 the author(s)

This is an Open Access article. Authors own copyright of their articles appearing in the Online Journal of Public Health Informatics. Readers may copy articles without permission of the copyright owner(s), as long as the author and OJPHI are acknowledged in the copy and the copy is used for educational, not-for-profit purposes. 


\section{Introduction}

Technology-assisted healthcare interventions have a long history of failed implementation ${ }^{[1]}$. It is generally agreed that the major attributing mediators for this repeated failure are social and organisational in nature rather than technical ${ }^{[2]}$. Variety of social and organisational factors contributes to low adoption of computer-assisted health interventions. These include organizational incompatibility, and integration with routine workflows ${ }^{[2]}$. Yet, numerous studies (e.g. ${ }^{[3],[4],[5]}$ ) contend that social and organizational compatibility issues have been insufficiently investigated in the development and implementation of computer-assisted healthcare interventions. More attention is normally put on the technological aspects at the expense of social and organizational issues. Failed sexual health and HIV/AIDS education interventions due to social and organisational issues are not uncommon even in the developed world ${ }^{[6]}$. The economic costs of failure of such interventions can create huge strains on the already overburdened economies of developing countries.

In response to the high prevalence of HIV/AIDS in Uganda since the early 1990's, Uganda adopted a comprehensive HIV/AIDS prevention strategy that acknowledged HIV as a threatening problem and involved the government and civil society in advocating Abstinence, Be faithful, Condom use (ABC). The result was a recorded success in HIV prevention. However, since 2005, HIV infections among Ugandans ages 15-49 have risen from $6.4 \%$ to $7.3 \%$ in men and to $8.3 \%$ in women, and are continuing to rise ${ }^{[7]}$. Reasons the increase in HIV infections particularly among young people include lack of HIV/AIDS knowledge and self-efficacy skills for HIV/AIDS prevention ${ }^{[8]}$. Schools accommodate many young people of diverse backgrounds, thus, they can be used as intervention sites to equip them with sexual health and HIV prevention knowledge and skills ${ }^{[9],[10],[11]}$.

As a resource-limited country that has been severely affected by HIV/AIDS, Uganda stands to benefit greatly from the integration of sexual health education interventions in schools. However, successful integration of sexual health education interventions in schools cannot be assumed especially given that they are health projects implemented in educational settings. Overall, mediators for successful implementation of school-based sexual health education programs remain under researched especially in developing countries ${ }^{[12],[13],[14],[15],[16]}$. Evaluating such interventions helps in identifying the needs and expectations of the target populations, which are crucial for obtaining community support and development of culturally accepted interventions. The only government-initiated school-based sexual health education intervention that was implemented in Uganda yielded no health benefits and suffered low prioritisation from schools $^{[17]}$. The rest of such interventions implemented in Uganda are mainly donor-funded pilot projects, which, for political reasons rarely publish results from failed interventions, yet such unsuccessful stories would provide good lessons for future interventions. This study conducted a qualitative cross-case analysis aimed to obtain rich insights into the facilitating or inhibiting mediators for the implementation of a school-based sexual health education intervention in Uganda. This was achieved by investigating why the intervention implementation was completed in one school but abandoned in another. 


\section{Methods}

\section{The World Starts With Me (WSWM) Intervention}

The intervention being evaluated by this study is known as the World Starts With Me (WSWM). Funded by the World Population Foundation, the WSWM was developed by Butterfly Works, SchoolNet Uganda and local experts in Uganda. It is a-14 lesson sexual health education intervention which is delivered to students by oriented intervention teachers using the intervention website (http://www.theworldstarts.org), printed handouts, the program CD ROM, and also it has an online support centre (http://schoolnetuganda.sc.ug/wswmonlinesupport/) for answering students' sexual health questions. First implemented in schools in Uganda in 2003, the WSWM has also been adapted to the local context and implemented in Kenya, India, Thailand, Indonesia, and Vietnam. In Uganda, the implementation normally starts in February to target new school entrants and implementation cycle ranges from 7-12 months. Topics covered include: 1) Protect Yourself: STIs and HIV/AIDS; 2) HIV/AIDS: U have a role 2 play 2; 3) Sexuality and Love, and 4) Pregnancy: 4 Girls and 4 Boys! This study set out to investigate why some schools implement the WSWM intervention successful while others abandon the implementation of the intervention. To answer this question, two schools are involved in this investigation: 1) the school that successfully implemented the WSWM intervention; known as the Completed Implementation School (CIS) for the purpose of this study; and 2) the school that abandoned the implementation; known as the Abandoned Implementation School (AIS).

\section{Selection of the Study Schools-CIS and AIS}

Study schools were selected based on the research question ${ }^{[18]}$. The first school to be selected was the CIS. The CIS is a government owned-army founded school based in the semi-urban western part of Uganda. Although there were many schools that had completed implementation of the intervention, the CIS was of particular interest for three major reasons: One, I had made initial contacts with the intervention teachers of the CIS during the WSWM workshop. These teachers expressed much interest in the research and promised to help me carry out this investigation in any way possible. Two, being a school in a military barracks with many warorphaned students and children from soldiers' separated families, these students were particularly vulnerable to HIV/AIDS. Three, this school was within my proximity and was therefore economically viable. By the time (Sept.2009) this research started, the CIS had just completed the first cycle of the WSWM intervention that was implemented from Feb.09-Sept.09. The intervention was delivered by teachers and student peer educators using the computer website, CDs and computer print-outs.

Next was the selection of a school suitable for taking part in a cross-case analysis. The three options provided a basis for selecting the next case ${ }^{[19]}$. These options are: 1) select a study to identify more themes for the extension of the emerging theory, and/or; 2) select a study to replicate the already selected cases in order to confirm the themes identified in the previous cases; or 3) select an extreme study that has opposing characteristics to the previous cases for the extension of the theory that is emerging.

The third option was adopted in this study, and a second case study - the Abandoned Implementation School (AIS) - was a polar opposite school that was selected mainly to see how 
the themes the emerged from the CIS manifest themselves in AIS. Particularly, after formulating an initial framework of influences for the successful implementation of the intervention from findings of the CIS, I was keen to investigate how the identified influences manifested themselves in an opposite case where the implementation of the intervention was abandoned. Generally, given that the intervention in the AIS was abandoned half-way through its implementation, exploring this case created an opportunity to compare its abandoned story with the successful story in the CIS.

The AIS is a Protestant Church-founded and a girls-only school situated in rural western Uganda. This school had around 1000 students, all of whom were boarders-staying at school during school days. In 2009, the intervention was implemented up to the $7^{\text {th }}$ lesson and abandoned before completing all 14 lessons. The implementation of the intervention begun in Feb.09, suffered many irregular attendances from both teachers and students, and was terminated in Oct.09. By the time this research started (Dec 2009), around two months had passed since its abandonment. Before its abandonment, the intervention was delivered using a combination of intervention handouts, $\mathrm{CDs}$ and the Internet. There was more than one school where the implementation was abandoned, but the AIS was selected on the basis of characteristics that sharply differed from that of the CIS. For instance, unlike the CIS which was urban-based and military-founded, the AIS was a rural-based and a Church-founded school. Thus the school was chosen in order to explore the distinction between rural and urban respondents and between government/military-founded and Church-founded, due to anticipated differences in social, institutional, cultures and beliefs, which may be central to implementation decisions.

\section{Selection of Participants and Data Collection}

Conducted in December'09, this investigation involved 16 semi-structured interviews with teachers and heads of schools of the CIS and AIS. Although a relatively long period of time has elapsed since the data was collected, the findings are still relevant since nothing has changed in the implementation process of the intervention. The study aimed to qualitatively investigate why the implementation of the intervention was completed in the CIS and abandoned in the AIS. To achieve this aim, it was necessary to select participants on the basis of their relationships with the intervention. Such purposive sampling is the commonly used sampling technique in qualitative research $^{20}$. The selected participants were: a) 4 school heads/deputy heads of the CIS and the AIS aged between 38 and 50, of which 3 were males, and 1 was a female; b) 4 intervention teachers who delivered the intervention in the CIS and AIS, of which 2 were females and 2 were males; c) I also interviewed 8 teachers from the CIS and the AIS in order to get objective perspectives from teachers that were not directly involved in the intervention. The average age for participants was 34. This study is part of the PhD research pursued in Manchester Business School, the University of Manchester-United Kingdom. Ethical approval to conduct this study was obtained from the Manchester Business School Research Ethics Committee. For confidentiality purposes, schools requested not to include their real names in the findings of this study. The formulation of interview questions was guided by the prevailing related literature ${ }^{[11],[21],[22],[23]}$. Questions focused on facilitators and inhibitors to the implementation of the intervention. 
Interview appointments were made, after which participants were interviewed in their offices at their respective schools during normal school hours. With consent from participants, all interviews were digitally recorded. Each interview lasted from 30-60 minutes.

\section{Data Analysis}

I transcribed the interviews, which enabled me to become familiar with emerging themes from different interviewees before the actual data analysis began ${ }^{[24]}$. Thematic data analysis was conducted to generate the results below, the summary of which is indicated in table 1 . To ensure that all the data effectively fitted within the identified themes, verbatim sections of all the interview transcripts were extracted on separate documents and arranged according to the themes.

\section{Results}

Table 1: Summary Cross-case comparison of responses from the CIS and the AIS

\begin{tabular}{|c|c|c|}
\hline & $\begin{array}{l}\text { Completed Implementation } \\
\text { School (CIS) }\end{array}$ & $\begin{array}{l}\text { Abandoned Implementation School } \\
\text { (AIS) }\end{array}$ \\
\hline Themes & \multicolumn{2}{|c|}{ properties } \\
\hline $\begin{array}{l}\text { Perceived } \\
\text { students } \\
\text { vulnerability }\end{array}$ & $\begin{array}{l}\text {-High student vulnerability due to } \\
\text { un-protective environments at } \\
\text { school, at home, and at school. } \\
\text { Included HIV/AIDS positive } \\
\text { students and previous sexual } \\
\text { offenders in the school }\end{array}$ & $\begin{array}{l}\text {-Relatively low student vulnerability } \\
\text { due to protective environment at } \\
\text { school, and at home }\end{array}$ \\
\hline $\begin{array}{l}\text { Teachers } \\
\text { confidence }\end{array}$ & $\begin{array}{l}\text {-Some challenges in tackling very } \\
\text { sensitive issues such as condom } \\
\text { use demonstration }\end{array}$ & $\begin{array}{l}\text {-feelings of embarrassment in } \\
\text { discussion sexual issues and } \\
\text { reservations about condom } \\
\text { demonstrations }\end{array}$ \\
\hline $\begin{array}{l}\text { Management } \\
\text { support and } \\
\text { priorities }\end{array}$ & -Supportive school administration & $\begin{array}{l}\text {-The new school administration that } \\
\text { took office after intervention } \\
\text { launching was unsupportive }\end{array}$ \\
\hline $\begin{array}{l}\text { Match with } \\
\text { routine } \\
\text { workflows }\end{array}$ & $\begin{array}{l}\text {-Although the intervention was not } \\
\text { school's main timetable, no extra- } \\
\text { academic lessons collided with the } \\
\text { intervention time }\end{array}$ & $\begin{array}{l}\text {-Intervention not school's main } \\
\text { timetable, yet, the new head of school } \\
\text { fixed academic lessons and exams } \\
\text { after-classes during the intervention } \\
\text { time. }\end{array}$ \\
\hline $\begin{array}{l}\text { Institutional } \\
\text { climate }\end{array}$ & $\begin{array}{l}\text {-Entire school environment owned } \\
\text { and supported the intervention, e.g. } \\
\text { other teachers voluntary } \\
\text { involvement in the intervention } \\
\text { activities }\end{array}$ & $\begin{array}{l}\text {-Unsupportive school environment, } \\
\text { e.g. other teachers claimed that the } \\
\text { intervention teaches prostitution and } \\
\text { that intervention teachers sexually } \\
\text { harass students. }\end{array}$ \\
\hline
\end{tabular}




\begin{tabular}{|l|l|l|}
\hline $\begin{array}{l}\text { Teaching } \\
\text { motivation }\end{array}$ & $\begin{array}{l}\text {-Teachers were committed to teach } \\
\text { without financial incentives but } \\
\text { stressed need for some form of } \\
\text { incentives. }\end{array}$ & $\begin{array}{l}\text {-Teachers refused to deliver the } \\
\text { intervention because they were not } \\
\text { paid and stressed they could not } \\
\text { resume teaching without being paid }\end{array}$ \\
\hline $\begin{array}{l}\text { Technology } \\
\text { issues }\end{array}$ & $\begin{array}{l}\text { Lacked enough computers and } \\
\text { internet connections: had 3 } \\
\text { computers (with internet } \\
\text { connection), and one television set } \\
\text { for delivering the intervention to } \\
\text { 150 students }\end{array}$ & $\begin{array}{l}\text { Lacked enough computers and } \\
\text { internet connections; 30 computers of } \\
\text { which only 5 had internet, compared } \\
\text { to 200 students enrolled for the } \\
\text { intervention. }\end{array}$ \\
\hline $\begin{array}{l}\text { Cultural/ } \\
\text { religious } \\
\text { compatibility }\end{array}$ & $\begin{array}{l}\text {-Incompatibility issues (such as } \\
\text { age appropriateness, } \\
\text { homosexuality and condom } \\
\text { advocacy) but teachers believed } \\
\text { that breaking the taboos was more } \\
\text { worthwhile than risking lives with } \\
\text { HIV/AIDS }\end{array}$ & $\begin{array}{l}\text {-Incompatibility issues and teachers } \\
\text { felt intimidated by bad } \\
\text { social/religious attitudes towards the } \\
\text { intervention, and were strongly } \\
\text { against condom advocacy and } \\
\text { homosexuality. }\end{array}$ \\
\hline $\begin{array}{l}\text { Community } \\
\text { involvement }\end{array}$ & \begin{tabular}{l} 
Involved communities and parents \\
\hline
\end{tabular} & \begin{tabular}{l} 
Community was not involved \\
\hline
\end{tabular}
\end{tabular}

Perceived students' vulnerability: The head teachers and intervention teachers in the CIS perceived the intervention to be of greater benefit due to high perceptions of students' vulnerability to HIV/AIDS and teenage pregnancies. This was due to the un-protective environments that students were exposed to both at school and at home. At home, many of the students were orphans whose parents had lost their lives in wars or from AIDS, while others were separated from their parents due to military operations:

The majority of our students lost their parents in wars, others lost their parents due to AIDS. And those whose parents are alive, their parents went for wars; they are in North, Iraq, Somalia, all over the world. And being in the barracks, they are very exposed, so, we needed the WSWM to ensure our students do not fall victims of AIDS and pregnancies [head teacher, CIS].

Being a mixed gender school located in the military barrack, there were possibilities of students' sexual harassment from barracks soldiers, city suburb dwellers as well sexual misconduct between students themselves. Some students were already living with HIV/AIDS while others were previous sexual offenders:

You see young people have a lot of challenges in this era of AIDS, with these ones here we used to have a lot of sexual misconducts and child pregnancies between students themselves, and sometimes between students and soldiers and even neighboring trading centre. Even some of our students have AIDS, others were once in prisons for rape, defilement e.t.c. so we needed to counsel them, and the WSWM provides a good avenue for that [intervention teacher, CIS]. 
The head teachers and intervention teachers of the AIS considered the intervention to be beneficial to students in equipping them with reliable information for pregnancy and HIV/AIDS pregnancy. However, compared to students' vulnerability in the CIS, the perception of students' vulnerability in AIS was relatively low due to students' protective environments both at school, since this was a rural-based girls-only school, and at home since students came from stable middle-income families:

Generally, the WSWM is helpful in equipping these young girls with information to prevent themselves from pregnancies and AIDS. We also have very strict roles on them here at school.... Most of their parents are educated middle income earners, so they should also be safe at home really [intervention teacher, AIS].

Teachers' Confidence: The CIS teachers faced challenges of feelings of embarrassment in dealing with issues that appeared too sensitive in class. Despite these challenges, teachers were able to deal with such issues during out-of-class private consultations:

I am confident because as a biology teacher, I have always taught related issues in. reproductive biology. But sometimes it becomes hard to discuss very private things before students because they are like my children. Yes, I am confident if students privately consult me after class [intervention teacher, CIS].

However, after-class private consultations were hindered by the prevailing sexual mistrust between teachers and students. It was urged that students should consult teachers of the same sex during after-class consultations:

...erm, some girls take it very far by simply coming to tempt male teachers into sex while pretending that say they have been dropped by their boyfriends and need some counselling. Sometimes I wish I had only boys. I think for very sensitive issues, students should privately consult teachers of the same sex after class [intervention teacher, CIS].

Noteworthy however is that despite the reported confidence, intervention teachers only informed students about condoms. No demonstrations of condom use were carried out due to doubts of age appropriateness:

We generally tell them about condoms but we encourage them to abstain. Yea, I could demonstrate condom use but I think it is better we just let them know about condoms for now. We give them information about the role of condoms, where to buy them, and how they should first read instructions before using them [intervention teacher, CIS].

Teachers in the AIS lacked self-efficacy and felt embarrassed and uncomfortable in both the classroom delivery of the intervention and in responding to some of the students' sexual health queries during out-of class private consultations: 
We give students some information but sometimes it is hard to discuss information that looks too private in class. To some extent yes I can answer those queries after class, but to some extent no because still some of them are either still too sensitive or I simply don't know the answers myself [intervention teacher, AIS].

The AIC teachers confessed that if the implementation of the intervention had continued, they would have skipped the topic on condom use due to both lack of skills and doubtfulness of the age appropriateness of the topic:

We could not have taught students about condoms... condoms should be removed from the WSWM program and left for experts like sexual health experts because for them they have the ability to discuss and demonstrate condom use confidently, and at right age. [intervention teacher, AIS].

Management support and priorities: In the CIS, the school administration was supportive of the intervention activities including attending head teachers' orientation, financially supporting teacher training workshops, and actively participating in intervention activities such launching and exhibitions:

...our head teacher is very cooperative in this program, for example he himself attended the head teachers' oriented workshop, and he contributes to the cost of our training workshops, and he was very helpful in mobilizing the entire school during the launching of this program. And I think you yourself saw his active participation at the exhibition [intervention teacher, AIS].

In contrast, the AIS experienced a change of administration a few months after the intervention was launched. Having never attended the intervention's head teachers' orientation workshop, the new head of school was administratively unsupportive of the intervention; including failure to contribute money for teachers' training workshops and lack of active involvement in the activities of the intervention:

The new head of school that joined us after the program was implemented didn't attend the head teachers' orientation workshop. Although I introduced the program to her, she kind of not prioritises it; our teachers are not facilitated to attend training workshops... [deputy head teacher].

Match with routine workflow: In both the CIS and AIS, there was no time allocated for the intervention on the schools' main timetable, as the intervention could not be matched with the schools' routine workflows:

...it would be good if the WSWM was timetabled like any other subject really. We teach the program in the evening as an extra-curricular activity. For dayscholars, we sacrifice and teach them on Saturday [intervention teacher, CIS]. 
Failure to put the intervention on the school's main timetable consequently resulted in students' inconsistent attendance due to clashes with other extra-curricular activities and housework for day-scholars:

Students keep coming in and out, because in the evenings when the program is run, they are already tired from the days work and end up not coming, and they also have to prepare for their night preps, and sometimes there are other things like football going on [intervention teacher. Sometimes the day-scholars don't turn up on Saturdays coz they have to some work at home CIS].

Noteworthy, however, is that although both schools never integrated the intervention into the main timetable, workflow mismatch was more seriously felt in the AIS, since the new head of school instead fixed academic lessons and exams after-classes during the same time the intervention was conducted. The adverse effect of this clash was intervention termination:

We stopped at lesson $7 \mathrm{coz}$ when the new head teacher came, she put academic lessons and exams in the evenings at the same time we were having our WSWM lessons... so we kind of give up on the WSWM because of this collision [intervention teacher, AIS].

Institutional climate: The overall school environment in the CIS was generally supportive of the intervention. Other than the intervention teachers, other teachers actively participated in the intervention activities, including voluntary engagement in intervention classroom sessions:

...yea, they [other teachers] are very much involved. In fact some even come into our classes and contribute to our discussions. And this helps students to learn from real life experiences of different people that have passed through the same challenges [intervention teacher, CIS].

In contrast, lack of intervention ownership from other teachers created unsupportive institutional environments for intervention implementation in the AIS.

Rather than collaboratively embracing the intervention, other teachers instead claimed that the intervention teaches prostitution and that intervention teachers sexually harass students:

...other teachers are completely not bothered about the WSWM program. In fact they say we are teaching these students prostitution, and when they see students come to us for sexual guidance, they think we are instead corning them for sex [intervention teacher, AIS].

Teaching motivation: Intervention teachers in both the CIS and the AIS were not paid any financial incentive for delivering the intervention. Yet, in addition to delivering the intervention lessons they had to teach their routine academic load. Nevertheless, teachers in the CIS were still committed to delivering the intervention in order to help students with HIV and teenage prevention information. They however stressed the need for either a teaching allowance or a reduction in academic teaching workload: 
It is a sacrifice really because we want to help our students so that they don't fall victims of AIDs and early pregnancies; and we have to teach our academic lessons too... We need to be given some token for teaching the program. Program donors need to do something, otherwise, at some point, we will have to give up, or they can reduce for us the academic lessons we are teaching ...[ intervention teacher, CIS].

In contrast, in the AIS, the intervention teachers' involvement was mainly driven by financial motives. Lack of financial motivation was one of the major driving mediators for intervention abandonment:

...when I had about the WSWM, I knew I was going to get some money for teaching it, so that's why I got involved knowing that I will not be committing my time for free. But because of no payments, we kind of pulled out. If you see project donors or leaders, tell them that they have to pay us if they ever want us to resume teaching the WSWM lessons [intervention teacher, AIS].

\section{Technological Issues}

Although the intervention is supposed to be web-based, there was a lack of sufficient computers and reliable internet connections in both the CIS and AIS. In the CIS, the school relied on only one connected computer for the delivery of the intervention to 150 students:

We don't have enough computers and internet. You have seen it yourself even. We need more connected computers, not just the three computers we have out of 150 students that need them... [intervention teacher, CIS].

Likewise, the AIS had computers and internet, the number of computers outnumbered the number of students; 30 computers, of which only 5 computers were connected to the internet, compared to 200 students that had enrolled for the intervention:

...there is also a problem of too many students in relation to the 30 computers we have here; and there are only 5 computers with internet [intervention teacher, AIS].

Lack of computers and internet connections not only de-motivated students, but also limited intervention accessibility, and made it impossible for students to fully utilise the potentials of the intervention including online discussion forums and interactive HIV/AIDS prevention games:

...much us we try to use the few computers available, students need to be able access the program on their own and practice the things like the interactive games, and you know being able to get involved in that online discussion. Such hands on experience would really be motivating to students [intervention teacher, CIS]. 
Lack of/unreliable internet connections interfered with email communications between the intervention leaders and teachers:

... which means when our internet is off, we have to travel five miles away from here and spend our own money in internet cafes in order to read emails from project leaders [intervention teacher, AIS].

Cultural compatibility with sex education: Despite the taboo-relatedness surrounding the subject of sexuality, intervention teachers in the CIS believed that breaking the taboos was less blameworthy than risking youthful lives with HIV/AIDS and pregnancy:

I see, but though some people are against it [sex education], the fact remains the fact; we have to give them the right information, we have to tell them to use condoms if they can't abstain, otherwise, we can't remain quite when AIDS is finishing our youth, when our girls are getting pregnancies and dropping out of schools [intervention teacher, CIS].

In contrast, intervention teachers in AIS felt significantly intimidated by bad societal attitudes that regarded the intervention as a sexually misleading intervention. They stressed the need for intervention tailoring to suit implementers' differing cultures and students' different needs and ages:

It can be disturbing to teach things that other people regard as immoral. And much as I think sex education is ok, we need to be very careful what information is culturally allowed, what information we should reveal to young people of different ages and origins [ teacher, AIS].

Teachers in both CIS and AIS suggested that lesson 7 be removed or revised due to cultural incompatibility. Lesson seven is about homosexuality and sexuality including different ways of playing sex and their precautions. They argue that the lesson gives students inappropriate details in addition to encouraging homosexuality, which is culturally unacceptable:

...Also lesson seven about sexuality should be removed or should be adjusted, it goes unnecessarily beyond what students should know, it encourages homosexuality too, which is against our culture [head teacher, AIS].

Religious compatibility with condom advocacy: Given the fact that AIDS has killed many young people, who are at the same time the most economically productive age group, intervention teachers in the CIS stressed the need to inform students about the alternative of using condoms despite the prevailing religious values against condom advocacy:

Although we are religious, we cant remain rigid about condom use when AIDS has killed many of our youth population, yet the youth are the future of this nation in terms of being economic productive. We need to tell them condom use as an option for those who fail to abstain [teacher, CIS]. 
In contrast, for religious and moral reasons, teachers and heads of school in the AIS were strongly against the intervention topic on condom use. Advocating sex abstinence was the only strategy allowed in this Church-founded school, since it was argued that condoms may hasten students' sexual activity:

... this being a Church-founded school; teachers cannot be immoral by starting teaching young people about condoms instead of abstinence. Personally, though I am in support of this program, I don't hide the fact that I am strongly against the lesson on condom use. Condoms can lead children to want to practice what they are taught [deputy head teacher, AIS].

Public sensitisation and involvement: The relationships existing between school and local communities impacted the adoption of the intervention. The CIS created awareness in the local communities by inviting some local leaders during the launching of the intervention, introducing the intervention during parents' meeting, as well inviting the public during end of intervention's students' exhibitions to witness students' personal testimonies, poems and drama:

In order to inform the surrounding communities and parents about the benefits of this program, we invited some influential members of the community when we were launching the WSWM, we also briefly tell parents about the WSWM when we call them for meetings. We also call them for the program exhibitions and they witness students' educative poems, drama and personal testimonies [head teacher, CIS].

Consequently, sensitising and involving parents and neighboring communities was instrumental in buying intervention support from people who would otherwise negatively perceive the intervention to be teaching prostitution.

Some parents were taking an active role by voluntarily getting involved in intervention sessions:

...I think making parents aware of the program, has kind you know informed them that we are not teaching prostitution as some thought at first, but that instead we are teaching students how to avoid AID, unwanted pregnancies, and live responsibly. I see some parents even come and attend our program sessions and join in our discussions [intervention teacher, CIS].

In contrast, in the AIS, there was a lack of public's/parents' sensitisation about the intervention. Intervention teachers lacked the confidence to sensitise parents about the intervention during parents' meetings due to perceptions of resistance and agenda-mismatch:

The parents and the general public needed to be informed of existence and benefits of the WSW, but, the strategy of introducing the program during parents' meetings could not work; you cant just introduce such stuff on people's agenda, unless it is done by the heads of school or project leaders because us we received some objections here and there [intervention teacher, AIS]. 


\section{Discussion}

This study intended to find out why was the implementation of the sexual health education intervention was completed in one school but abandoned in another. As discussed below, the success of the implementation of the intervention depended on the extent to which students were perceived to be vulnerable, teachers' level of confidence in delivering the intervention, teaching motivation, management support, match with routine workflows, institutional climate, and social- cultural and religious compatibility of the intervention.

Perceived students' vulnerability: Perceptions of the important role of the intervention in helping vulnerable students prevent themselves from contracting HIV and suffering unintended pregnancies motivated CIS to adopt the intervention. Low perceptions of students' vulnerability to HIV constrained the adoption of the intervention in the AIS. This difference in perceptions of vulnerability was could have been because the CIS was an army-founded mixed gender school located in the military barracks with many orphans and students from soldiers' separated families. There were possibilities of students' sexual harassment from barracks soldiers, and city suburb dwellers, as well as sexual misconduct between students themselves. Some of the students in the CIS were already living with HIV/AIDS while others were previous sexual offenders. In contrast, in the AIS, perception of students' vulnerability was generally low due to perceived protective environments both at school and at home. This was because, the AIS was a Church-funded girls-only school with students from middle income families, many of whom had both of their parents alive. Generally, compared to the AIS, the CIS considered the implementation of the intervention a priority rather than an option. The demonstrated positive relationship between teachers' and head teachers' perceived benefits of adopting the intervention and the actual adoption of the intervention is consistent with contentions of behavioral scientists that stress a relationship between anticipated adoption benefits and adoption decisions ${ }^{[25],[26]}$. Noteworthy however is that although the anticipated benefits implicated by the mentioned behavioural scientists focus on target audiences whose behaviours need to change, this study demonstrates that the influence of the perceived benefits extends from the individual target audience to influential stakeholders.

This indicates the need to involve students, teachers and heads of schools in planning, developing and implementing school-based sexual health interventions.

Teachers' Confidence: Teachers' low levels of self-efficacy greatly hindered the fidelity of the intervention implementation. Teachers in both the CIS and the AIS felt uncomfortable discussing sensitive sexual issues. However, unlike in the AIS, teachers in the CIS, notwithstanding some sexual mistrust between teachers and students, were confident to deal with some sensitive issues during out-of-class private consultations, and to inform students about condoms during classroom delivery. Feelings of embarrassment and discomfort, and lack of skills in discussing sensitive sexual issues greatly constrained the would-be skills-based and interactive nature of the intervention and constrained role plays and condom use demonstrations. This consequently resulted in delivery of mainly factual and superficial information. Although the teachers attended a 5-day intervention orientation workshop, they expressed a need for more training, as it was argued that limited training contributed to their low levels of self-efficacy in delivering the intervention. Related studies report teachers' feelings of embarrassments, lack of skills and 
confidence, mainly due to limited training, as major barriers to effective implementation of sexual health education in schools ${ }^{[11],[16],[21],[27]}$. Possibilities of sexual mistrust between students and teachers are not uncommon ${ }^{[22]}$. Separating classes into same-sex groups may minimise lack of confidence in classroom discussions ${ }^{[29]}$. Allocating same-sex teachers to groups may minimise sexual mistrust between student and teachers especially during out-of-class consultations. Noteworthy however, separating classes into same-sex groups for the entire curriculum may constrain the depth of discussions about topics that require views of mixed sexes ${ }^{[23]}$. These topics include discussions about gender norms. This approach may also constrain confidence in sex communications with the opposite sex.

Management support and priorities: The school administration in the CIS was supportive of the intervention activities, including attending head teachers' orientation workshop, financially supporting teacher training workshops, and was actively involved in intervention launching and exhibition. Lack of support from the school management was a major cause of the abandonment of the implementation of the intervention in the AIS. There was a change of school administration after the intervention was launched, and the new head teacher did not support and prioritise the intervention. She did not financially support intervention teacher training workshops, which led to teachers' failure to attend training workshops. She also introduced institutional changes that adversely affected the intervention; including fixing evening academic lessons and exams that clashed with the intervention delivery time. Although there was inconsistency in students' intervention attendance, due to timetabling problems in both the CIS and the AIS, this problem was more significant in the AIS than in the CIS. Students' inconsistent attendance in the CIS was mainly attributed to clashes of the intervention with other extracurricular activities and home works, while that of the AIS was largely attributable to clashes with evening academic lessons and exams fixed by the new head of school. Administrative support is a significant factor for the success of school-based sexual health education interventions ${ }^{[22]}$, and the effective implementation of technology-assisted health interventions ${ }^{[5]}$.

Match with routine workflows: In both CIS and AIS, the absence of a timetabling policy left teachers in helpless and they struggled to allocate some time for the intervention. The intervention could not be allocated time on the schools' core timetables.

Delivering the intervention as an extra-curricular activity in the evenings and weekends resulted into students' inconsistent attendance and largely contributed to intervention abandonment in the AIS's worst case scenario. Inability to complete school-based sexual health education curricula in Uganda due to time constraints is not uncommon ${ }^{[30]}$. Worldwide, poor timetabling policy is an impediment to successful implementation of school-based sexual health education interventions ${ }^{[16]}$. Even in healthcare settings, workflow mismatch between the institutional routine workflow and the technology-assisted innovation being introduced are not uncommon ${ }^{[4]}$.

Teaching motivation: Intervention teachers complained of teaching overload, as the intervention was an extra teaching load, moreover without any financial incentives for its delivery. There seemed to be disagreements about who should motivate and facilitate intervention teachers; intervention donors expected schools to motivate their teachers while schools also expected the donors to motivate the teachers. AIS teachers stressed that they were not willing to resume the intervention without financial motivation, while CIS teachers cautioned that they will stop delivering the intervention if they are not getting some form of incentives e.g. 
reduction in academic load or financial motivation. In contrast, although teachers in the CIS were still committed to delivering the intervention due to high perceptions of students' vulnerability to HIV and unintended pregnancies, they also stressed the need for teaching allowance or reduction in academic teaching workload. Related to this, some behavioural researchers ${ }^{[31],[32],[33]}$, suggest that incentives can motivate and encourage the adoption of behavioural change interventions.

Technological aspects: There was a lack of computers and reliable internet connections in both the CIS and AIS. In particular, the CIS had only three computers with internet connection and one television set to deliver the intervention to 150 young people, while the AIS had limited computers and internet connections; compared to 200 young people in the intervention, the school had 30 computers, of which only five were connected to the internet. Lack of computers and internet limited accessibility to the intervention, led to partial or no coverage of discussion forums and interactive HIV/AIDS prevention games, and created communication barriers between the teachers and intervention leaders. Yet, the technology-based would have been beneficial in many ways including providing unlimited accessibility of the intervention, offering an opportunity to tailor the intervention to students' varying sexual health information needs, and ensuring confidentiality of the otherwise sensitive sexual health information ${ }^{[10]}$. Noteworthy however is that despite the potential advantages, results indicate that compared to the technological aspects, the social and orgnisational issues played a major role in the implementation and adoption of the intervention. Related literature ${ }^{[3],[5]}$ acknowledge that compared to technical aspects, social and organisational issues are major determinants of effective implementation of technology-assisted healthcare interventions.

Social-cultural and religious compatibility with sex education and condom advocacy: Teachers and heads of schools in both the CIS and the AIS expressed concern over the inappropriate sexual details of lesson 7 (Sexuality and Love) and claimed that the lesson encourages homosexuality, and gives students unnecessary details on sexuality. They argued that the contents are culturally unacceptable, and that the topic on homosexuality should be removed. Despite the taboos surrounding the subject of sexual health, teachers in the CIS embraced the intervention as they believed that breaking the taboos was justified compared to risking youthful lives with HIV/AIDS and pregnancy.

They were committed to informing students about the alternative of using condoms despite the prevailing religious values against condom advocacy. In contrast, teachers in AIS reported feeling significantly intimidated by the social-cultural and religious incompatibilities that associated some of the interventions topics with students' prostitution, sexual harassment, sex experimentation and increased sex activity. They were strongly against the intervention topic on condom use and associated condom advocacy with promoting sexual immorality by encouraging sexual activity. Being a Church-founded school, it believed in abstinence-only interventions preferably delivered by Christian role models, as they claimed possibilities of teacher-student sexual harassment in teacher-delivered interventions. Although there is currently no evidence to support such claims ${ }^{[13]}$, concerns about young people's sex experimentation as a result of sexual health education (in particular condom education) have long been reported to be the major concern of parents and teachers ${ }^{[22],[34]}$. Such presumptions assume students' ignorance of sexuality as well as inactivity in sexual issues, yet there is evidence, students as young as 11 years are sexually active ${ }^{[9]}$. Apparently, with or without sexual health education, it would be hard 
to conclude other than that young people engage in sexual activity. Participants stressed the need to tailor the intervention to suit implementers' differing cultures and young people's different needs and ages. Age-appropriateness has long been an adults' biggest concern about schoolbased sexual health interventions ${ }^{[35]}$. It cannot be assumed that young people are all at the same level of sexual activeness and neither can it be assumed that they all have the same sexual health education needs. It is generally agreed that successful implementation of school-based sexual health education programs depends on their compatibility with social-cultural and religious values prevailing among adopting communities ${ }^{[11],[21]}$. Related literature ${ }^{[1],[2]}$ about the adoption of technology-assisted health innovations attribute low adoption rates of such interventions to incompatibility with organisational valves and beliefs.

Stakeholder sensitisation and involvement: Findings demonstrate that stakeholder involvement is crucial for the successful implementation of school-based sexual health education interventions. Unlike the AIS, the CIS created awareness of the benefits of the intervention in the local communities, and involved local leaders, parents and other teachers in intervention activities such as launching, exhibition, classroom discussions. Awareness about the intervention was also continuously raised during parents' meetings. Peer educators and intervention alumni were utilised as role frameworks for the advocacy and promotion of the intervention. In addition, unlike the AIS, the CIS environment was supportive of the intervention; for instance other teachers voluntarily actively participated in the intervention activities, including voluntary engagements in intervention classroom sessions, and encouraging young people to adopt the intervention. Sexual reproductive experts from the neighbouring hospitals and health organisations were often invited to talk to students as well as to help teachers with some emerging challenging issues regarding their sexual and reproductive health. The CIS approach of stakeholder involvement consequently created intervention support from the public that would otherwise have negatively perceived the intervention. Its school-community links were sources of expertise advice. The CIS suggested involving parents through student-parent intervention assignments i.e. giving students holiday or take home assignments that require to be discussed with parents/guardians. Interactive child-parent assignments is a potential strategy for encouraging parent-child sex communication ${ }^{[11],[27]}$. Overall, community involvement in the development and implementation of sexual health education programs is vital in obtaining community support and development of culturally accepted interventions.

\section{Implications and Conclusion}

School-based sexual health education interventions can reach young people of diverse backgrounds and equip them with knowledge and skills for preventing themselves against HIV/AIDS, unwanted pregnancies, and live responsibly. However, being a health project implemented in educational settings, many social and institutional issues can present challenges. This study has explored the facilitators and inhibitors of the implementation of the school-based sexual health education intervention (WSWM) based on experiences of two schools that implemented the intervention in Uganda. These schools were the CIS, which completed the implementation of the intervention, and the AIS, which abandoned the intervention half-way the implementation. Experiences from these schools suggest that the "successful" implementation was strongly influenced by interplay of many mediators, which were more favourable in the "successful" school than in the "failure" school. These mediators were: perceived students' 
vulnerability to HIV and unwanted pregnancies; teachers willingness to deliver the interventions in addition to their routine academic workloads, school management support; match with schools' routine workflow and formal curricula, social-cultural and religious compatibility with sex education and condom advocacy, the level of stakeholder involvement in the intervention planning and implementation; and the extent to which the pre-existing academic teachers are professionally equipped to deliver sexual health education interventions. The intervention orientation given to teachers was considered inadequate. Even with adequate training, given its sensitive nature, teaching sexual health education in school environments is a challenge that is globally experienced by teachers in both developing and developed countries ${ }^{[11],[16]}$. The biggest challenge appeared to be that of social-cultural and religious incompatibility. There were high levels of resistance from stakeholders in the AIS who claimed that such interventions encourage promiscuity among young people. They believed that young people are more likely to 'experiment out' what they learn from such interventions e.g. condom use experimentation. Based on the findings, this study recommends the following:

Emphasising policy-level advocacy and putting in place school level and national level policies for prioritising sexual health education, including: (1) ensuring direct implementation of the intervention by the Ministry of Education to improve intervention prioritisation. Implementing the intervention by a donor-funded NGO was rather generally seen, by some stakeholders, to be politically motivated by their own ambitions; (2) committing schools to ensure fidelity of implementation of the intervention, Otherwise, even a well-designed and comprehensive intervention may not yield positive behavioural impacts if some sessions are skipped or partially covered, as was the case of condom use education in this study. Another way of improving prioritisation of sexual health education is to cover the subject under a broader compulsory health promotion subject and to ensure proper time tabling. For instance, in the United Kingdom, sexual health education has recently been made part of the new Personal, Social and Health Education (PSHE), and in 2011, it became a statutory part of the national curriculum ${ }^{[36]}$.

Supporting schools and teachers including: (1) putting strategies for ensuring availability of computers and intervention consumables; (2) setting standards for teacher-student relationships; (3) setting strategies for teacher training in skills-based and interactive sexual health education e.g. through pre-service training at teacher training institutions and in-service training offered by experienced sexual health educators;

(4) implementing related but age-appropriate interventions in primary schools; (5) selecting intervention teachers on grounds of personal interest and enthusiasm in young people's sexual health; (6) ensuring good schools' administrative support; (7) provision of incentives to intervention teachers e.g. by giving teaching allowances and/or reducing the academic teaching load; in cases where the intervention is a major part of the school curriculum, teachers can be completely relieved from teaching other subjects; (8) teachers should have on-going access to specialists to enable continuous competency development and to help them in dealing with challenging issues that might emerge in the course of delivering the intervention. This may include linking intervention teachers to sexual health specialists from local health centres.

Employing a variety of intervention supplementary and activities and stakeholder involvement, such as: (1) social mobilisation through community sensitisation and involvement; (2) 
implementing parallel interventions at community level to supplement school-based interventions and cater for vulnerable young people who are not in schools; (3) sensitising and clearing away misconceptions associated with sex education; (4) involving all relevant stakeholders including young people, parents, teachers, educationists, policy makers, practitioners and religious leaders in major phases of the intervention, including training needs analysis, planning, design and implementation phases; (5) identifying network opinion leaders who can champion the intervention implementation; A multi-sector collaboration approach that includes all relevant sectors and stakeholders is a sine qua non for intervention acceptability, sustainability, and the subsequent adoption of advocated behaviours. Thus, there is a need for sufficient solidarity between different sectors, policy makers, leaders of the intervention, educationalists, schools, and local communities in the planning, design and implementation of the intervention.

Concerns of age-appropriateness can be minimised by tailoring the intervention to better meet the differing needs of young people of different age groups ${ }^{[10]}$. Rather than the generic 'one-size fits all' interventions which assume that young people have similar needs, interventions need to target specific preventive methods to specific individuals. In intervention tailoring: (1) messages of abstinence and delay of sex onset can be targeted at young people who are not yet sexually active; (2) messages of condom use and secondary abstinence can be targeted at those who are already sexually active. Another worthwhile alternative approach can be to give young people all the correct information they need in order to protect themselves against HIV/AIDS and pregnancy irrespective of their needs, while at the same time warning them of the dangers of early and increased sex activity.

To sum it all, this research makes important contributions on an area that has been inadequately researched. Lack of rigorous evaluation of school-based sexual health education interventions in Africa has been of greatest concern ${ }^{[13]}$. Uganda has had only one government-initiated schoolbased sexual education program, which suffered low prioritization from schools and yielded no health benefit ${ }^{[17]}$. The WSWM - the donor/NGO-initiated sexual health education intervention evaluated in this study improved students' sexual health knowledge and attitudes but had no significant impacts on sexual behaviours ${ }^{[9]}$. Yet, although knowledge and attitudes are important health attributes, the most important one is health behavioural change, which leads to health outcomes. Many of the donor-initiated school-based sexual health education interventions implemented in Uganda are really evaluated.

Those that carry out evaluations do not publish the results of failed interventions. Yet, such unsuccessful stories would provide good lessons that can be used to improve the implementation of sexual health education interventions. Many of the implementation mediators identified in this study have been reported in literature although not necessarily in the contexts of Uganda. Although often given less attention, compared to technical/technological aspects, social and institutional issues were major determinants of effective implementation and adoption of intervention.

This study adds to the existing literature by employing an innovative approach that explored the implementation of the intervention by practically comparing the CIS' success story with the AIS' failure story. The evidence-based recommendations outlined above can guide potential 
replications, improvements, and policy formulation in subsequent school-based sexual health education interventions.

\section{Acknowledgement}

This work is part of a $\mathrm{PhD}$ research that was financially supported by the Commonwealth Scholarship Commission in the United Kingdom, and supervised by Dr. Donal Flynn at Manchester Business School, the University of Manchester-United Kingdom.

\section{Corresponding Author}

Angella Musiimenta

Mbarara University of Science and Technology, and Bishop Stuart University Kakoba

Email: angellamusiimenta@yahoo.com

\section{References}

[1] Heeks, R., Mundy, D. and Salazar, A. (1999). Why Health Care Information Systems Succeed or Fail. Manchester School of Environments and Development, Working Paper 9, Manchester, UK . Available at:

www.sed.manchester.ac.uk/idpm/publications/wp/igov/igov_wp09.htm. Accessed September 12 2012].

[2] Hare, K., Whitworth, B. and Deek, P. (2006). Identifying Barriers to IT Adoption in Clinical Health Care: A Pilot Study. Healthcare and Informatics Review. Available at: http://hcro.enigma.co.nz/website/index.cfm?fuseaction=articledisplay\&FeatureID=070906. Accessed November 16 2012].

[3] Munir, S.K. and Kay, S. (2003). Organizational Culture Matters for System Integration in Health Care. AMIA Annual Symposium Proceedings 484-488. Available at:

http://www.pubmedcentral.nih.gov/articlerender.fcgi?artid=1480353. Accessed October 16 2012.

[4] Toussaint, P. and Berg, M. (2000). Electronic Patient Record as an Organizational Artefact. Hershey, PA, USA: Ideal Group Publishing. Available at: http://portal.acm.org/citation.cfm?id=373168.373207\&coll=GUIDE\&dl=GUIDE\&CFID=15 151515\&CFTOKEN=6184618. Accessed November 21 2011].

[5] Day, K. and Norris, T. (2006). The Leadership in Times of Crisis During Change Due to Health IT Projects: Health Care and Informatics Review. Available at:

http://hcro.enigma.co.nz/website/index.cfm?fuseaction=articledisplay\&FeatureID=050906. Accessed August 01 2012].

[6] O'Grady, L. (2006). Consumer HIS Education in HIV/AIDS: A Pilot Study of a Web-based Video Workshop. BMC Medical Informatics and Decision Making, doi:10.1186/1472-69476-10.

[7] Uganda AIDS Commission National:HIV Prevention Strategy 2011-2015.2011. Available at: http://www.aidsuganda.org/documents/NPS.pdf. Accessed May 14, 2013.

[8] Hulton LA, Cullen R, K. W. Perceptions of Risks of Sexual Activity and their Consequences among Ugandan Adolescents Studies in Family Planning. 2000;31(1):35-46. 
[9] Musiimenta A. A Controlled Before-After Evaluation a computer-based HIV/AIDS education on Students' Sexual Behaviours, Knowledge and Attitudes. Online Journal of Public Health Informatics. 2012a;4(1).

[10] Musiimenta A. Information Technology Issues in Sexual Health Education. International Journal of Information Systems in Developing Countries. 2012b;53(3).

[11] Musiimenta A. Contextual Mediators influencing the Effectiveness of Behavioural Change Interventions: A Case of HIV/AIDS Prevention Behaviours. Online Journal of Public Health Informatics. 2012c;4(2).

[12] Shepherd J, Kavanagh J, Picot J, Cooper K, Harden A, Barnett-Page E, et al. The Effectiveness and Cost-effectiveness of Behavioural Interventions for the Prevention of Sexually Transmitted Infections in Young People aged 13-19: A Systematic Review and Economic Evaluation.2010. Available at: http://www.hta.ac.uk. Accessed July, 202012.

[13] UNESCO. International Technical Guidance on Sexuality Education: An Evidence Informed Approach for Schools, Teachers and Health Educators. 2009. Available at: http://unesdoc.unesco.org/images/0018/001832/183281e.pdf . Accessed November 2, 2012

[14] Paul-Ebhohimhen VA, Poobalan A, ER. VT. (A Systematic Review of School-based Sexual Health Interventions to Prevent HIV/AIDS in Sub-Saharan Africa. BMC Public Health. 2008.

[15] Magnussen L, Ehiri JE, Ejeri H, PE. J. Interventions to Prevent HIV/AIDS among Adolescents in Developing Countries: Are they effective? International Journal of Adolescent Medical Health. 2004;16:303-23.

[16] Buston K, Wight D, Hart G, S. S. Implementation of a Teacher-delivered Sex Education Programme: Obstacles and Facilitating Conditions. Health Education Research, Theory and Practice 2002;17(1):59-72.

[17] Hyde K, Ekatan A, Kiage P, C. B. HIV/AIDS and Education in Uganda: Window of Opportunity? . Washington, DC: World Bank.2002.

[18] Eisenhardt KM. Building Theories from Case Study Research. The Academy of Management Review. 1989;14(4):532-50.

[19] Yin R. Case Study Research. Beverly Hills: Sage; 1984.

[20] Bryman A. Social Research Methods, Oxford: Oxford University Press; 2001

[21] Smith G, Kippax S, P A, P. T. HIV/AIDS School-Based Education in Selected Asia-Pacific Countries. Sex Education. 2003;3(1):3-21

[22] Power R, Langhaug L.F, Nyamurera T, Wilson D, Bassett MT, FM. C. Developing Complex Interventions for Rigorous Evaluations - A Case study from Rural Zimbabwe. Health Education Research, Theory and Practice. 2004;19:570-5.

[23] Wight D, C. A. From Psycho-Social Theory to Sustainable Classroom Practice: Developing a Research-based Teacher-Delivered Sex Education Programme. Health Education Research. 2000;15:25-38.

[24] Bryman A. Social Research Methods, $3^{\text {rd }}$ ed. Oxford: Oxford University Press;2008.

[25] Rosenstock I.L, Strecher VJ, MH. B. Social Learning Theory and the Health Belief Model. Health Education Quarterly. 1988;15(2):175-83.

[26] Ajzen I. Attitudes, Personality and Behaviour. Milton Keynes: Open University Press; 1988.

[27] Kirby D. D. K. Recommendations for Effective Sexuality Education Programs. Unpublished Review prepared for UNESCO. 2009. 
[28] Wight D, Raab GM, Henderson M, Abraham C, Buston K, G H, et al. Limits of Teacher Delivered Sex Education: Interim Behavioural Outcomes from Randomised Trial. British Medical Journal. 2002;324(1430).

[29] Kirby D, Korpi M, RP B, HH. C. The Impacts of the Postponing Sex Involvement Curriculum among Youth in California. Family Planning Perspectives. 1997;29(3):100-8.

[30] Kinsman J, Harrison S, Kengeya-Kanyondo J, Kanyesigye E, Musoke S, Whitworth J. Implementation of a Comprehensive AIDS Education Programme for Schools in Masaka District, Uganda. AIDS Care, Psychological and Social-Medical Aspects of HIV/AIDS. 1999;11(5):591-601.

[31] Kotler P, Roberto E, N. L. Social Marketing: improving the Quality of Life. Thousand Oaks, CA: Sage; 2002.

[32] Hill R. The Marketing Concept and Health Promotion: A Survey and an Analysis of "Recent Health Promotion Literature". Social Marketing Quarterly. Social Marketing Quarterly. 2001;2:29-53.

[33] Dolan P, Hallsworth M, Halpern D, King D, I. V. MINDSPACE: Influencing Behaviour through Public Policy. Institute for Government. 2010. Available at: http://www.instituteforgovernment.org.uk/content/133/mindspace-influencing-behaviourthrough-public-policy. Accessed June 20, 2012.

[34] Mitchell K, Nakamanya S, Kamali A, G. W. Community-based HIV/AIDS Education in Rural Uganda: Which Channel is most effective? BMC Medical Informatics and Decision Making. 2001;16:411-23.

[35] Flicker S, Goldberg E, Read S, Veinot T, McClelland A, Saulnier P, et al. HIV Positive Youth's Perspectives on the Internet and eHealth. Journal of Medical Internet Research. 2004;6(e2).

[36] Teachernet. Personal, Social, Health and Economic (PSHE) education. 2009 Available from: http://www.teachernet.gov.uk/teachingandlearning/subjects/pshe/. Accessed December $18,2011$. 